\title{
Comparative Fingerprint and Extraction Yield of Medicinal Herb Phenolics with Hepatoprotective Potential, as Determined by UV-Vis and FT-MIR Spectroscopy
}

\author{
Simona ZAVOI ${ }^{1}$, Florinela FETEA ${ }^{1}$, Floricuta RANGA ${ }^{1}$, Raluca \\ M. POP ${ }^{1}$, Anca BACIU ${ }^{2}$, Carmen SOCACIU ${ }^{1 *}$ \\ ${ }^{1}$ University of Agricultural Sciences and Veterinary Medicine, Faculty of Agriculture, 3-5 Mănăşstur \\ Street, Cluj-Napoca, Romania; carmen.socaciu@usamvcluj.ro ( ${ }^{*}$ corresponding author) \\ ${ }^{2}$ Center for Applied Biotechnology CCD-BIODIATEC, Proplanta Cluj-Napoca, Romania
}

\begin{abstract}
The present study was aimed to compare the polyphenolic composition of six medicinal herbs, from wild flora of Romania. The plants investigated, Cynara scolimus (artichoke), Taraxacum officinalis (dandelion), Chelidonium majus (celandine), Hypericum perforatum (St. John's wort), Silybum marianum (Mary thistle) and Lycopodium clavatum (Wolf's claw) are known, to have hepatoprotective action. Using in parallel glycerol-water, ethanol-water and methanol, the solvent-dependence of the extract fingerprint and composition in bioactive molecules was studied by UV-Vis and Infrared (FT-MIR) spectrometry. The extraction yields, calculated as an extraction factor (EF) were superior in acidic methanol comparative to glycerin and ethanol, favorising the increase in phenolic acids against flavonoid derivatives. Based on the differences of polarity between the three solvents used, higher EF values were obtained for dandelion, artichoke, celandine and St. John wort, more rich in phenolic acids than flavonoids. Mary thistle and Wolf's claw had lower concentrations of phenolics, but higher content of lignans and terpenoids. Based on the FT-MIR peaks from 8 regions, for each plant extract, has been determined the fingerprint region between 900 and $1500 \mathrm{~cm}^{-1}$ and identified the specific functional groups. A good, significant correlation was found between the concentration of total phenolics calculated by UV-Vis spectrometry and FTIR methods, after calibration with gallic acid. The value of the MIR signal at $1743 \mathrm{~cm}^{-1}$ may be considered a good indicator of phenolics concentration in such extracts. Combined UV-Vis and FTIR spectroscopy are recommended as rapid and reliable tools to investigate the fingerprint and to predict the composition of medicinal plants or to evaluate the quality and authenticity of different standardized formulas.
\end{abstract}

Keywords: FT-MIR, hepatoprotection, medicinal herbs, quality and authenticity, UV spectrometry

\section{Introduction}

The traditional herb medicines showed, since centuries, beneficial effects on health promotion, out of side effects, as compared with synthetic drugs. It is also known that their composition is dependent on many ontogenic or genotypic factors influenced by their environment, age, time of harvesting, drying and storage, as well the solvent used to obtain extracts. Due to their natural heterogeneity, the quality of herbs from wild environments shows great fluctuations, so their standardization has been extensively promoted during the last years, the following three attributes being verified: authenticity, purity and assay of their action (Hussain et al., 2009; Yadav and Dixit, 2008). The identification of phytochemicals' fingerprint by chromatography and spectroscopy may provide effective information about qualitative and quantitative composition of herbal medicines and their pattern recognition can be achieved by chemometry (Bender, 2005; Maloney, 2004) and used to discriminate among different herbs and extracts, with noticeable role in the development of standardized formulas, like other pharmaceuticals to make these remedies evidence-based medicines, (Giri et al., 2010; Liang et al., 2004; McGuffin et al., 1997; Yadav and Dixit, 2008), according to WHO requirements (WHO, 2003)

The evaluation of a herbal product by its metabolomic fingerprinting can be accomplished by appropriate methods, including HPLC with UV (DAD), ELSD, MS detection or GC-MS, HPTLC-densitometry, FT-MIR, NIR, NMR or a combination of these techniques (Fan et al., 2006; Giri et al., 2010; Gong et al., 2006; 2009; Hashimoto and Kameoka, 2008; Li et al., 2008; Mattoli et al., 2006).

The UV-Vis spectroscopy offer a simple, cheap and easy-to-use technique to identify and quantify the main phytochemicals, discriminating between the lipophilic and hydrophilic phytochemicals, in relation to the polarity of the extraction solvent.

Fourier transform infrared spectroscopy (FTIR) offers a rapid and non-destructive investigation, easy to 
use to fingerprint herbal extracts or powders, is relatively uncommon compared with chromatographic and classical methods (Hussain et al., 2009a; Li et al., 2004b; Liu et al., 2006). The use of attenuated total reflectance (ATR) device evolved rapid FTIR measurements of liquids such as oils and plant extracts, allowing the identification and quantification of valuable plant biomarkers (Schultz and Baranska, 2007).

The herbs, known traditionally, to have hepatoprotective action are generally rich in polyphenols with high antioxidant potential (Mary thistle, artichoke, dandelion, greater celandine, St. John's wort, etc.) since major liver diseases are related to oxidative stress and cellular necrosis (Negi et al., 2008;Utrilla, 1996).

Dandelion (Taraxacum officinalis) is an old remedy for grandular unbalances, used in the therapy of liver diseases for the biliary stimulation, normalization of blood circulation, dieresis and toxins release. Its bitter substances (eudesmanolides and germacranolides) named generically "taraxacin", are anti-vomitives and antioxidants (Jeon et al., 2008). Dandelion contains as well flavonoids (7-D glucosides of apigenol and luteoline) and steroids (stigmasterol, sitosterol, ergosterol) which block the de novo synthesis of cholesterol and are competitors of cholesterol deposition (Williams et al., 1996). It contains also inulin with protective action against diabetes and liver diseases (Schütz et al., 2006), similarly to artichoke.

Since many years it was reported that artichoke $(C y$ nara scolimus) induces regeneration of rat liver (Maros et al., 1966), mainly due to cynarin, a phenolic derivative which stimulates liver cell excretion (Li et al., 2004a; Wang et al., 2003). Luteolin, a flavone which inhibit the de novo cholesterol synthesis as well sesquiterpene lactones has coleretic and cholagogue effects (Saenz Rodriguez et al., 2002). The leaf extract of artichoke reduces mild dispepsia (Marakis et al., 2002) and have antioxidant potential, as demonstrated on leukocytes (Perez-Garcia et al., 2000).

Greater celandine (Chelidonium majus) is a medicinal poppy (Bone, 1996) with beneficial antihepatotoxic and meanwhile controversial effects on liver (Duke, 1985; Mitra et al., 1992; 1996). It is rich in alkaloids (Gu et al., 2010), mainly chelidonin, a naphtofenantridin derivative which stimulates the enzymatic production in liver and pancreas, it is colecystokinetic and antispastic (Gilca et al., 2010; Hriscu et al., 1980). It was demonstrated experimentally to be antiinflamator, anticancerigenic şi antimicrobian (Vavreckova et al., 1996) being recommended in cyrosis and chronic hepatitis therapy. Using a standardized extract ( $4 \mathrm{mg}$ chelidonin for 6 weeks) for pacients with digestive syndroms, a significant reduction of symptoms was reported (Ritter and Schatton, 1993). Sanguinarine is another alkaloid found in celandine which acts as a colchicine-like cytostatic (Lopus and Panda, 2006; Malikova et al., 2006) with antiviral, antiinflamatory and antibacterial potential (Zdařilová et al., 2006). Meanwhile, overdoses are recommended to avoid, due to its alkaloid charge and hepatotoxicity (Benninger et al., 1999).

Mary thistle (Silybum marianum) is known to have hepatoprotective action and to be a hepatocyte activator (Ferenci et al., 1989; Salmi and Sarna, 1982), being used not only as tea but also in some standardized drugs such as Silimarine (generic name of lignan flavonoids, a mixture of silibine, silibinine, silicristine and silidianine). Silibine is the most active derivative, the extracts being standardized at $70-80 \%$ silibine. The mechanisms involved in its hepatoprotective action are diverse and include antioxidant and antiperoxidation effects (Basaga et al.,1997; Bosisio et al., 1992), detoxifying effect (Baer-Dubowska et al., 1998; Miguez et al., 1994), antiviral action (McPartland, 1996) and glutathion protection (Cabrera, 1996). Silimarine protects hepatocytes agaist toxic effects of acetaminophen, ethanol, carbon tetraclorine (Bosisio et al., 1992; Favari and Perez-Alvarez, 1997; Muriel et al., 1992), decrease the fibrosis by III-peptide procolagen inhibition (Feher et al., 1989) and inhibit cytochrome P 450 (BaerDubowska et al., 1998).

St. John's wort (Hypericum perforatum) contains several compounds with hepatoprotective properties, by synergistic action of hypericins and phenolics. Hypericins are reddish-violet condensed anthraquinones found $(0,1-$ $0,2 \%)$ in leaves and flowers. Due to their UV fluorescence, are photoactivated in sun, being good candidates for tumor photodynamic therapy. It has also anti-depressive and antiviral, has cholagogue and choleretic properties (Ali and Olivo, 2002; Kurth and Spreeman, 1998). Flavonoid glucosides (rutoside) protects the liver against oxidative stress, especially by its action on superoxid dismutase (Istudor, 2003). The condensed tannins and hyperforin, have antibiotic effects, inhibits cytochrom P450 CYP3A4 şi CYP2C9 (Barnes et al., 2001; Gitea et al., 2007; Kurth and Spreeman, 1998; Nahrstedt and Butterweck, 1997).

Wolf's claw (Lycopodium clavatum) is a less studied herb, which contains more than 35 alkaloids and other biomolecules, whose structure and pharmacologic effects are not yet elucidated The bioactive molecules are lycopodine, clavatoxin, clavolonin, clavatin, liclanitin, annapodin, izolzcopodin, as well nicotine, triterpenoids and sterols, flavonoids, radium (known as an antitumor mineral). Triterpenoids and sterols are stimulators of digestive system, antialergic, prevent the cholesterol and fats deposition, may have good effects on liver tumor inhibition, anti-inflamatory and antimicrobial action (BetancorFernandez et al., 2003).

The present study aimed to compare the fingerprint of different extracts of the above-mentioned medicinal herbs, collected from wild flora of Romania. The dependence of the extract composition on the solvent polarity (glycerol-water $v s$ ethanol-water $v s$ acidic methanol) was studied by UV-Vis spectrometry and Infrared (FT-MIR) fingerprints. 
84

\section{Materials and methods}

\section{Medicinal plants and preparation of extracts}

Six types of medicinal plants, from wild flora of different areas of Transylvania, Romania were investigated. The plants were numbered as follows: 1-Cynara scolimus (artichoke), 2-Taraxacum officinalis (dandelion), 3-Chelidonium majus (celandine), 4-Hypericum perforatum (St. John's wort), 5-Silybum marianum (Mary thistle), 6-Lycopodium clavatum (Wolf's claw). Aliquots of $15 \mathrm{~g}$ from each dried and grounded plant (selected from $100 \mathrm{~g}$ mix of leaves, stems and flowers) were extracted in $85 \mathrm{ml}$ solvent: methanol $90 \%$ in water, acidulated with $1 \%$ hydrochloric acid (M) or ethanol $93 \%$ in water (E) or $30 \%$ glycerin in water (G). After sonication $30 \mathrm{~min}$, centrifugation and filtration, the clear extracts were kept in the deep freezer until analysis.

\section{$U V$-Vis spectra and calculation of extraction factors}

The UV-V is spectra were recorded (700-200 nm) for each extract (M, E or G) using a Jasco V 530 Spectrofotometer. There were identified the maxima wavelenghts specific for phenolics (280 and $330 \mathrm{~nm})$, carotenoids (420-470 nm) and/or chlorophylls (663 nm).

To compare the yields of extraction in different solvents it has been calculated the Extraction Factors (EF) of bioactive molecules from each extract, considering the ab-

Tab. 1. The absorption maxima $\lambda_{\text {max }}(\mathrm{nm})$ of each plant extract from UV-Vis spectra and the mean values calculated $(\mathrm{X} \pm \mathrm{SD})$ for extraction factors $(\mathrm{EF})$

\begin{tabular}{|c|c|c|c|c|}
\hline Plant (nr.) & $\lambda_{\text {max. }}(\mathrm{nm})$ & $\begin{array}{c}\text { EFE } \\
\text { Ethanol }\end{array}$ & $\begin{array}{c}\text { EFG } \\
\text { Glycerin }\end{array}$ & $\begin{array}{c}\text { EFM } \\
\text { Methanol }\end{array}$ \\
\hline \multirow{3}{*}{$\begin{array}{l}\text { Dandelion } \\
\text { (1) }\end{array}$} & 279 & $7.69 \pm 0.55$ & $231.64 \pm 10.50$ & $240 \pm 0.55$ \\
\hline & 320 & $7.96 \pm 0.58$ & $201.24 \pm 9.20$ & $280 \pm 10.50$ \\
\hline & 396 & $2.07 \pm 0.12$ & $106.09 \pm 7.50$ & 0 \\
\hline \multirow{4}{*}{$\begin{array}{l}\text { Artichoke } \\
\text { (2) }\end{array}$} & 247 & $83.08 \pm 3.08$ & $43.85 \pm 1.50$ & 0 \\
\hline & 295 & $82.94 \pm 3.88$ & $41.19 \pm 1.35$ & $91.71 \pm 6.50$ \\
\hline & 327 & $97.05 \pm 5.02$ & $42.86 \pm 1.65$ & $73.31 \pm 2.80$ \\
\hline & 663 & 0 & 0 & 6.03 \\
\hline \multirow{5}{*}{$\begin{array}{c}\text { Celandine } \\
\text { (3) }\end{array}$} & 212 & 0 & $255.36 \pm 11.34$ & 0 \\
\hline & 275 & $67.79 \pm 2.05$ & $103.96 \pm 6.90$ & $288 \pm 12.10$ \\
\hline & 330 & $48.94 \pm 1.86$ & $72.96 \pm 2.50$ & $219 \pm 10.13$ \\
\hline & 396 & $13.14 \pm 0.90$ & $42.86 \pm 1.98$ & 0 \\
\hline & 663 & 0 & 0 & $9.81 \pm 0.40$ \\
\hline \multirow{2}{*}{$\begin{array}{l}\text { St. John's } \\
\text { wort (4) }\end{array}$} & 270 & $33.89 \pm 1.80$ & $137.71 \pm 8.98$ & $422 \pm 21.05$ \\
\hline & 330 & $19.03 \pm 1.10$ & $82.68 \pm 3.98$ & $238 \pm 11.08$ \\
\hline \multirow{3}{*}{$\begin{array}{c}\text { Mary } \\
\text { thistle (5) }\end{array}$} & 280 & $19.76 \pm 1.06$ & $34.88 \pm 1.98$ & $142 \pm 9.58$ \\
\hline & 325 & $14.63 \pm 1.01$ & $29.26 \pm 1.27$ & $77 \pm 3.10$ \\
\hline & 395 & $19.76 \pm 1.12$ & $18.01 \pm 1.18$ & 0 \\
\hline \multirow{5}{*}{$\begin{array}{l}\text { Wolf's } \\
\text { claw (6) }\end{array}$} & 233 & $57.91 \pm 2.90$ & 0 & $108.31 \pm 9.80$ \\
\hline & 284 & $31.92 \pm 1.75$ & $25.81 \pm 1.39$ & 0 \\
\hline & 324 & $29.94 \pm 1.50$ & $24.96 \pm 1.35$ & $59.4 \pm 2.80$ \\
\hline & 397 & $12.46 \pm 1.80$ & $3.99 \pm 0.84$ & 0 \\
\hline & 652 & 0 & 0 & $2.69 \pm 0.54$ \\
\hline
\end{tabular}

sorption values $\left(A_{\lambda_{\max }}\right)$ recorded for each $\lambda_{\max }$, multiplied with the dilution factor $(\mathrm{d})$. The formula applied was:

$\mathrm{EF}=\mathrm{A}\left(\lambda_{\max }\right) \mathrm{xd}$

The results were expressed as mean values of four samples per plant and in duplicated extracts from each plant. The content of total phenolics was determined by Vis spectrometry, using the standard method, Folin Ciocalteu (Singleton, 1999)

\section{FT-MIR measurements}

The Fourier Transform Infrared spectrum (FTIR) of each extract was recorded in the MIR region, from 4000 to $900 \mathrm{~cm}^{-1}$, and 64 scans were accumulated for each spectrum using the Horizontal Attenuated Total Reflection (HATR) device, using a Shimadzu Prestige 2 FTIR spectrometer (with apodization Happ-Genzel ). The spectral data were processed using the IR solution Software Overview (Shimadzu) and OriginR 7SR1 Software (OriginLab Corporation, Northampton, USA). The spectra were registered as fluid ( $\mathrm{M}, \mathrm{E}, \mathrm{G}$ ) but also evaporated extracts (these data are not shown). Total phenolics were determined also by FTIR method, either using the intensity of the peak at $1742 \mathrm{~cm}^{-1}$ or from the area of the region $950-1900 \mathrm{~cm}^{-1}$, considering the calibration curve with pure gallic acid (range of concentrations 5 to $30 \mathrm{mg} / \mathrm{ml}$ methanol).

\section{Results and discussions}

Extraction factors of bioactive molecules, based on $U V$ Vis spectra

The comparative UV-Vis spectra of the ethanol (E) and glycerin $(G)$ extracts of the six medicinal plants were recorded (data not shown), as well in methanolic extracts (M) (Fig. 1), methanol being considered a "reference" solvent known to extract phenolics and terpenoids from these plants.

Based on their specific spectra, the absorption maxima $\left(\lambda_{\text {max. }}\right)$ of each plant extract and the mean values of extraction factors (EF) were calculated for each solvent (E, G and $\mathrm{M})$ (Tab. 1).

To have an integrated image of the differences between plants, solvent type and concentrations of bioactive molecules extracted, the EF mean values at 270-290 nm (for phenolic acid derivatives extracted in E, G, M) (EFE1, EFG1, EFM1) and at 317-340 nm (for flavonoid derivatives) (EFE2, EFG2, EFM2) for each of the 6 plants were represented (Fig. 2).

According to Tab. 1 and Fig. 2 data, it has been noticed that extraction factors in acidic methanol were superior to glycerin and ethanol, especially for phenolic acids (EFE1, EFG1, EFM1) comparing to flavonoid derivatives (EFE2, EFG2, EFM2). Based on the differences of polarity between the three solvents used (glycerin the most polar, followed by methanol and ethanol) it has been noticed high- 

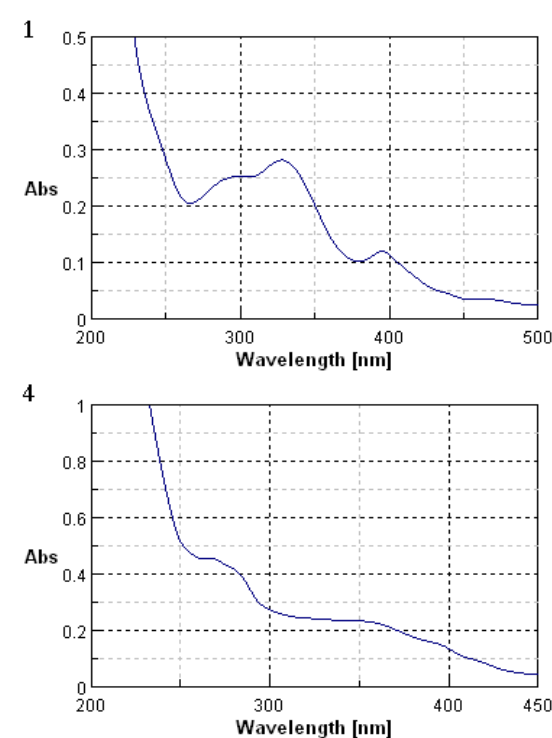

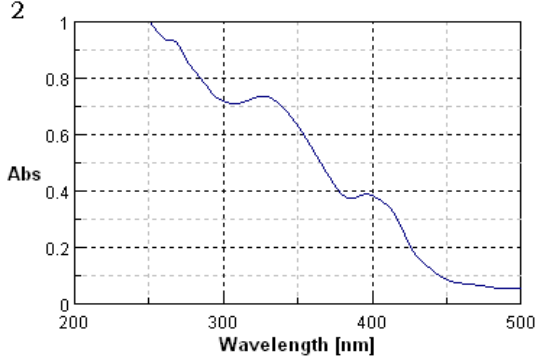

5

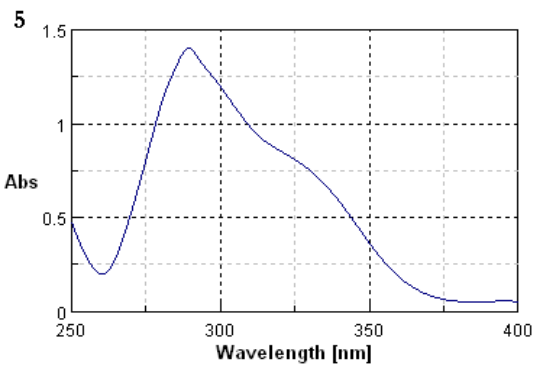

3

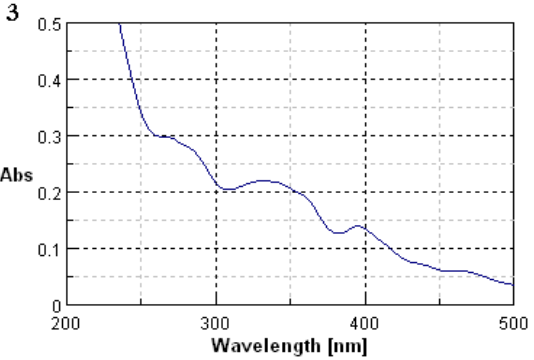

6

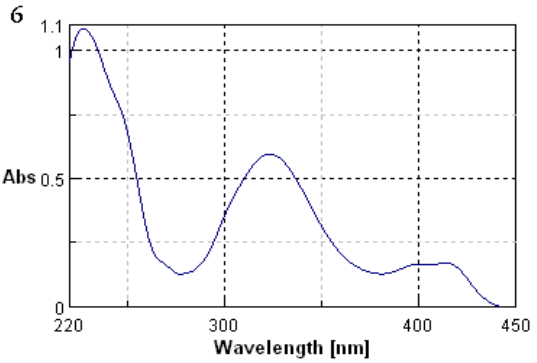

Fig. 1. Comparative UV-Vis spectra of methanolic (M) extracts of Taraxacum officinalis (1); Cynara scolimus (2); Chelidonium majus (3); Hypericum perforatum (4); Silybum marianum (5); Lycopodium clavatum (6)

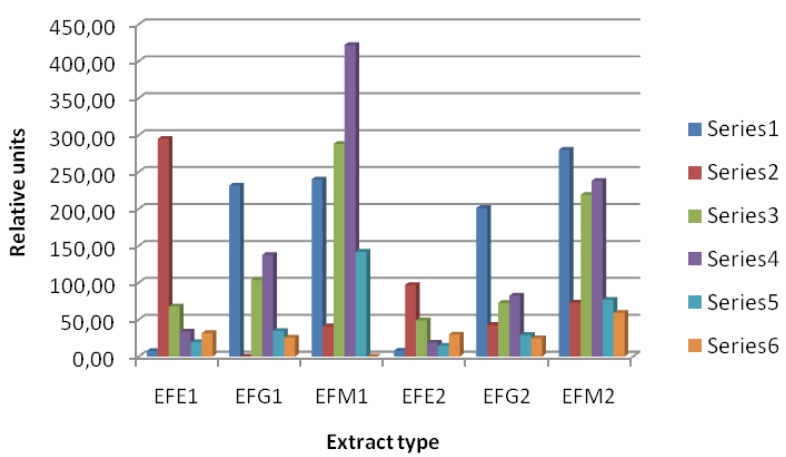

Fig. 2. Comparative mean values of extraction factors (EF) in different solvents (ethanol-E, glycerin-G, metahnol-M) at 270$290 \mathrm{~nm}$ (EFE1, EFG1, EFM1) and 317-340 nm (EFE2, EFG2, EFM2) for each of the studied plants (series 1-6)

er EF values for dandelion (1), celandine (3) and St. John wort (4), more rich in polar molecules, such as phenolic acids and flavonoids. Plants 1 and 3 had similar EF in M and $G$, plant 2 (artichoke) was better extracted in ethanol and was more rich in phenolic acid derivatives. St.John's wort (4) components were two times better extracted in methanol than glycerin, and low EF values in ethanol, an indication of polar active molecules. Mary thistle (5) and Wolf's claw (6) contained reduced concentrations of phenolics, but high absorptions in methanol at 280 and 233 $\mathrm{nm}$, respectively, which might be attributed to higher concentrations of lignans and terpenoids.

For therapeutic reasons it has been consider that ethanol extracts or evaporated methanolic extracts can provide higher concentrations of bioactive molecules from these plants. Anyway, as it was reported recently, methanolic extracts showed hepatoprotective activity against Carbon Tetrachloride-Induced Hepatotoxicity in Rats (Ahsan et al., 2009). Of course for humans the total elimination of methanol (under vacuum) is a condition to have a safe standardized extract.
Tab. 2. Absorption peak areas of different regions (1-8) of FTMIR spectra recorded for methanol extracts $(M)$ of the studied medicinal plants

\begin{tabular}{ccccccc}
\hline Wavenumber $(1 / \mathrm{cm})$ & 1 & 2 & 3 & 4 & 5 & 6 \\
\hline $3300-3350(8)$ & 0.70 & 0.92 & 0.63 & 0.82 & 0.93 & 0.80 \\
$2800-3000(7)$ & 0.89 & 0.81 & 0.98 & 0.90 & 0.82 & 0.75 \\
$1500-1520(5)$ & 0.35 & 0.22 & 0.30 & 0.52 & 0.32 & 0.30 \\
$1300-1440(4)$ & 0.72 & 0.80 & 0.80 & 0.95 & 0.43 & 0.63 \\
$1170-1230(3)$ & 0.90 & 0.90 & 0.92 & 1.15 & 0.78 & 0.80 \\
$1000-1100(2)$ & 1.35 & 1.45 & 1.32 & 1.50 & 1.05 & 1.28 \\
$<1000(1)$ & 0.50 & 0.78 & 0.60 & 0.85 & 0.60 & 0.52 \\
\hline $\begin{array}{c}\text { Total phenolics } \\
\text { (by FTIR) } \\
\text { mg GA eq./ml M }\end{array}$ & 11.33 & 11.03 & 11.16 & 10.18 & 8.05 & 9.26 \\
\hline $\begin{array}{c}\text { Total phenolics (by } \\
\text { Vis spectrometry) } \\
\text { mg/GA eq./ml M }\end{array}$ & 9.307 & 9.066 & 9.171 & 8.386 & 6.669 & 7.642 \\
\hline
\end{tabular}

\section{FT-MIR fingerprint}

The FT-MIR spectra $\left(4000-900 \mathrm{~cm}^{-1}\right)$ of E and G extracts of each plant were registered and the specific wavenumbers and intensities were considered (data not shown). Fig. 3 presents the FT-MIR spectra of M extracts and Tab. 2 includes the corresponding absorption peak areas for specific regions (1-8). In Tab. 2 , is included the total phenolics concentration in methanol $(\mathrm{M})$ extracts determined by FTIR and by Vis spectrometry.

The functional groups identification was based on the FTIR peaks attributed to stretching and bending vibrations. Eight areas (marked from 1 to 8) (Fig. 3) were identified in the MIR domain and the fingerprint region was localized between 900 and $1500 \mathrm{~cm}^{-1}$ (areas 1-4).

Area $1\left(<1000 \mathrm{~cm}^{-1}\right)$ corresponds to $\mathrm{C}-\mathrm{H}$ bending vibrations from isoprenoids, area $2\left(997-1130 \mathrm{~cm}^{-1}\right)$ to stretching vibrations $\mathrm{C}-\mathrm{O}$ of mono-, oligo- and carbohydrates, with signals at 1030, 1054, 1104, and $1130 \mathrm{~cm}^{-1}$, while area $3\left(1150-1270 \mathrm{~cm}^{-1}\right)$ corresponds to stretch- 
86

1

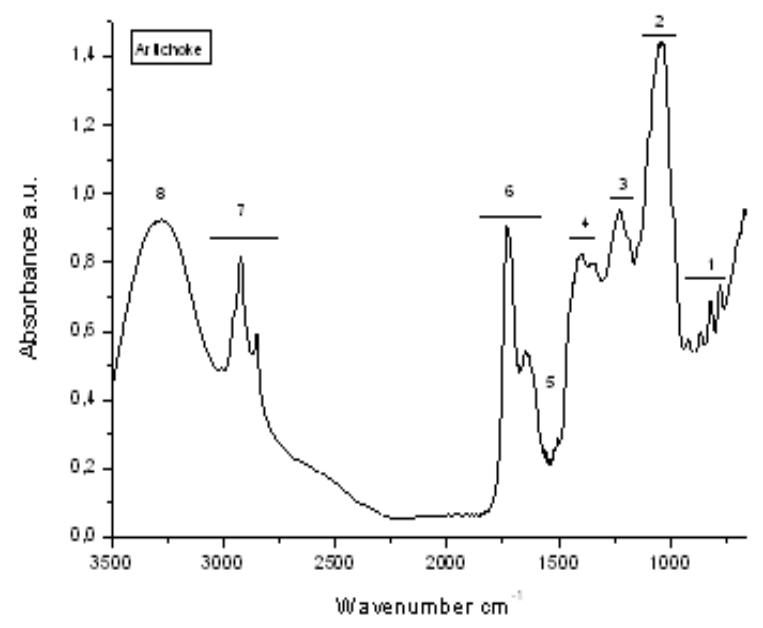

2

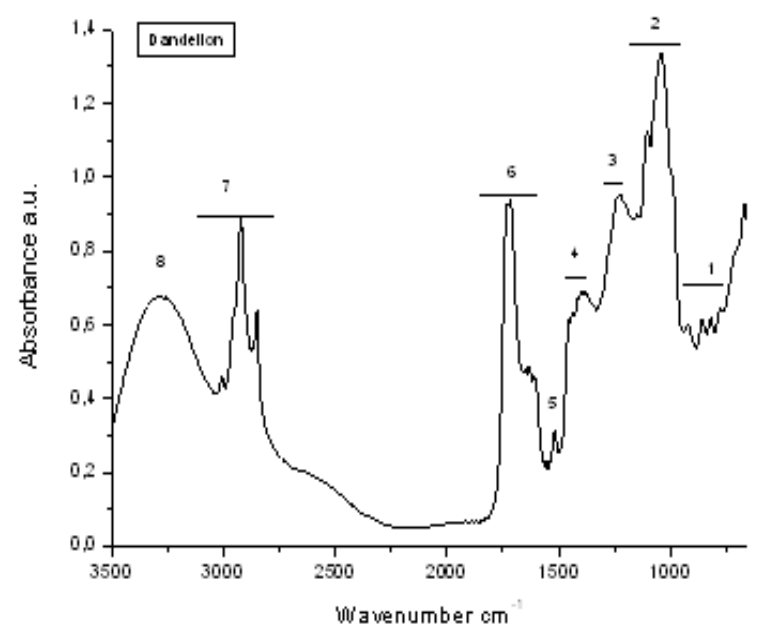

3

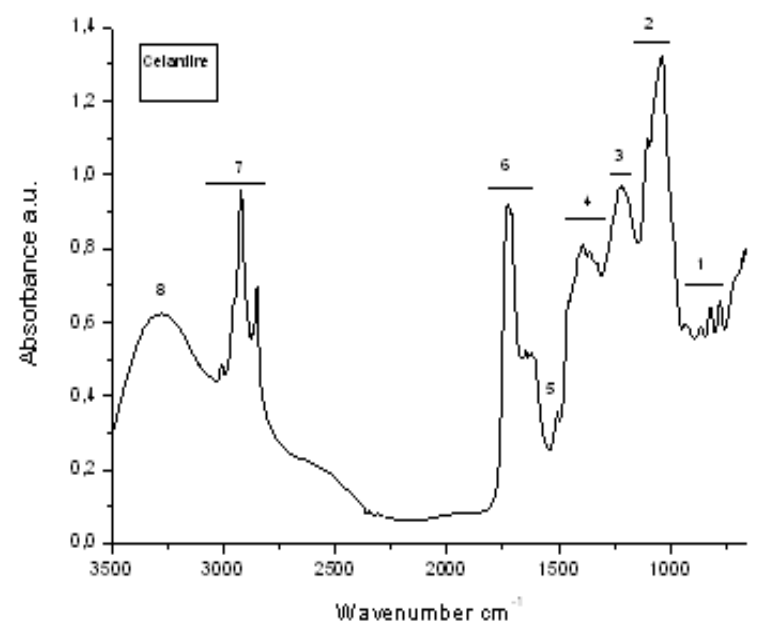

4

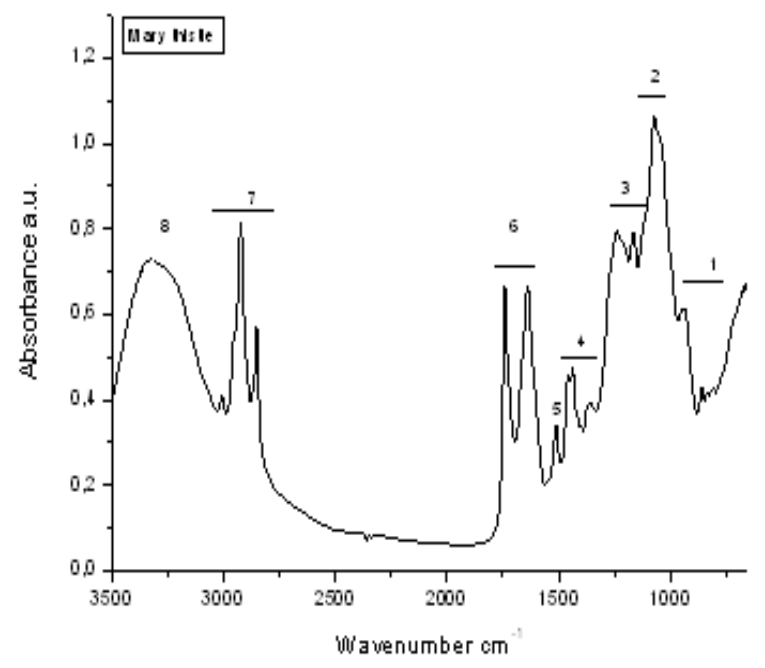

5

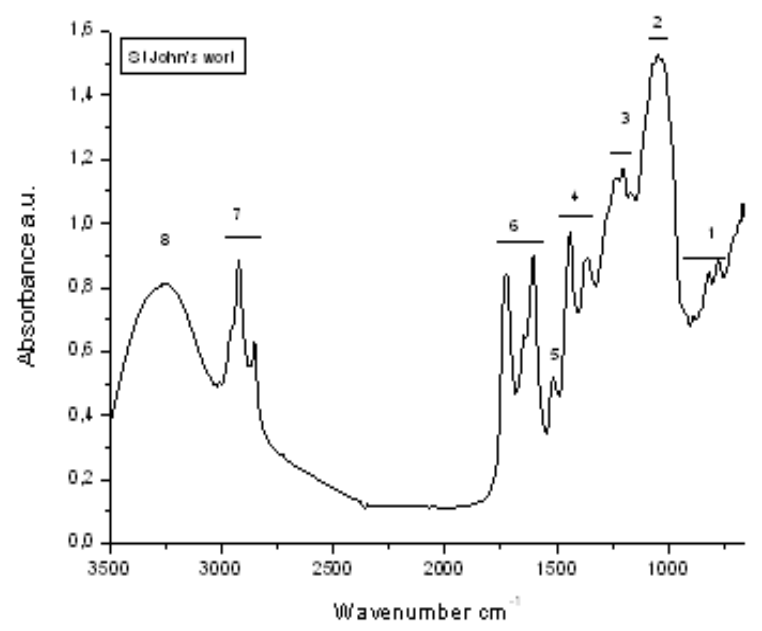

6

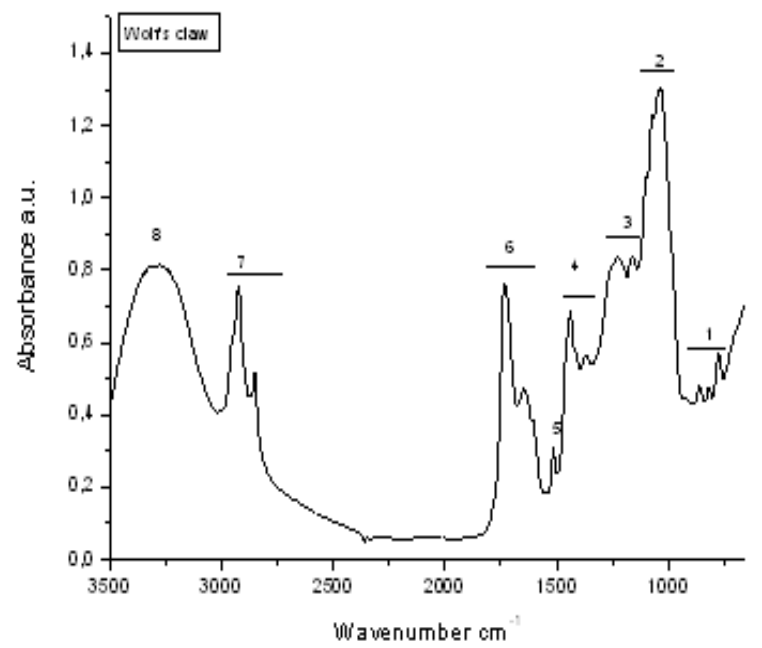

Fig. 3. The FTIR fingerprint of the metanolic (M) extracts of the studied plants: Cynara scolimus (1); Taraxacum officinalis (2); Chelidonium majus (3); Silybum marianum (4); Hypericum perforatum (5); Lycopodium clavatum (6). The specific regions are numbered 1 to 8 


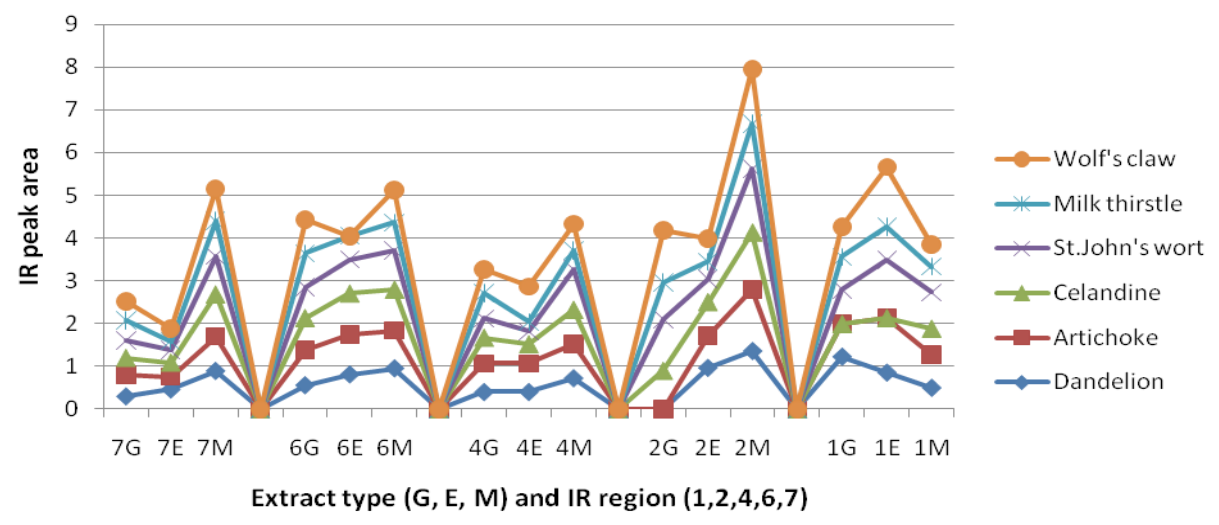

Fig. 4. Comparative representation of the differences recorded between the areas of regions 1, 2, 4, 6, 7 corresponding to each plant extract ( ethanol-E, glycerin-G or methanol-M)

ing vibrations of carbonyl $\mathrm{C}-\mathrm{O}$ or $\mathrm{O}-\mathrm{H}$ bendings. Area $4\left(1300-1450 \mathrm{~cm}^{-1}\right)$ correspond to stretching vibrations $\mathrm{C}-\mathrm{O}$ (amide) and C-C stretchings from phenyl groups, while area $5\left(1500-1600 \mathrm{~cm}^{-1}\right)$ to aromatic domain and $\mathrm{N}-\mathrm{H}$ bending vibrations. Area 6 is a complex one (1600$1760 \mathrm{~cm}^{-1}$ ), corresponding to bending vibrations $\mathrm{N}-\mathrm{H}$ (amino acids), $\mathrm{C}=\mathrm{O}$ stretchings (aldehydes and cetones, esters) as well to free fatty acids $\left(1710 \mathrm{~cm}^{-1}\right)$ and glycerides $\left(1740 \mathrm{~cm}^{-1}\right)$. Area $7\left(2800-2900 \mathrm{~cm}^{-1}\right)$, corresponds to $\mathrm{C}-\mathrm{H}$ stretching vibrations specific to $\mathrm{CH}_{3}$ and $\mathrm{CH}_{2}$ from lipids, metoxy derivatives, C-H (aldehydes), including cis double bonds. Area $8\left(3350-3600 \mathrm{~cm}^{-1}\right)$ corresponds to stretching vibrations of $\mathrm{OH}$ groups (from water, alcohols, phenols, carbohydrates, peroxides) as well from amides $\left(3650 \mathrm{~cm}^{-1}\right)$.

In alcoholic extracts there are absorption peaks in the domain $1300-1800 \mathrm{~cm}^{-1}$, more than in glycerin, e.g. at 1558,1517 and $1467 \mathrm{~cm}^{-1}$, as well in the region 1380 $1450 \mathrm{~cm}^{-1}$. Such differences were noticed also by other authors, after processing the second derivative (Liu si col, 2006) in Angelica extracts, where typical signals specific to cellulose and hemicelluloses at 3413 and $1054 \mathrm{~cm}^{-1}$. The signals at 1642 and $1536 \mathrm{~cm}^{-1}$ correspond to amide I band (carbonyl group) and amide II (stretching $\nu \mathrm{CN}+$ bending $\delta \mathrm{NH}$ ) found in glycoproteins. Carbonyl groups have specific signals at $1743 \mathrm{~cm}^{-1}$. Fig. 4 represents the differences

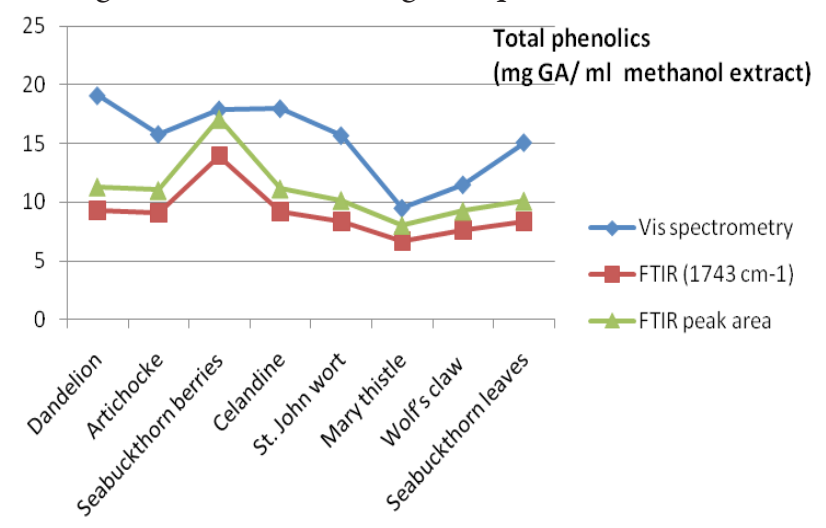

Fig. 5. Comparative representation of the total phenolics (expressed as $\mathrm{mg} \mathrm{GA} / \mathrm{ml}$ metanolic extract), calculated from Vis spectrometry, from FTIR peak intensity at $1743 \mathrm{~cm}^{-1}$ and from FTIR peak area recorded between the IR areas 1, 2, 4, 6, 7 corresponding to each plant extract ( $\mathrm{E}, \mathrm{G}$ or $\mathrm{M})$.

Looking to region 1 (specific to terpenoids) it has beennoticed that plants 6,5 and 4 had higher peak areas in ethanol, similarly to results from UV-spectra. In the other IR regions ( 4 and 6) no significant differences between the three solvents extracts were noticed, but in regions 2 (corresponding to glucosides) and 7 (lipids), in all plant extracts, the $M$ extract was significantly more charged in molecules that $\mathrm{E}$ or $\mathrm{G}$ extracts.

Finally it has been compared the phenolic concentrations, determined by FTIR method, based on the peak intensity at $1743 \mathrm{~cm}^{-1}$ and total phenolics calculated from Vis spectrometry. A significant $(p<0.05)$ correlation factor was obtained, as shown in Fig. 5. It is known that the measurement by Vis spectrometry is not specific to phenolics and can overestimate concentrations, while the FTIR method using the peak area $\left(950-1900 \mathrm{~cm}^{-1}\right)$ estimation can give also false results. It can be consider in this case that measurements based on FTIR absorption intensity at $1743 \mathrm{~cm}^{-1}$ offer the best evaluation of the phenolics concentration in these plants. Generally the concentrations oscillated between 15 to $20 \mathrm{mg} \mathrm{GA} / \mathrm{ml}$ methanolic extract (15000-20000 ppm), in agreement with other determinations.

\section{Conclusions}

The data presented in this study showed that UV-Vis spectrometry and FT-MIR spectroscopy are adequate techniques to fingerprint comparatively and to evaluate the extraction yield of medicinal herbs with hepatoprotective potential. Based on UV spectrometry, the extraction yields were superior in acidic methanol comparative to glycerin and ethanol, increased in phenolic acids comparative to flavonoid derivatives. Based on the differences of polarity between the three solvents used, higher extraction yields were obtained for dandelion, artichoke, celandine and St. John wort, more rich in phenolic acids than flavonoids. Mary thistle and Wolf's claw had lower concentrations of phenolics, but higher content of lignans and terpenoids. Based on the FT-MIR spectroscopy, for each plant extract it was determined the fingerprint region 
88

to be located between 900 and $1500 \mathrm{~cm}^{-1}$ and it has been identified the specific functional groups.

All FTIR data will be correlated and further validated with the detailed HPLC analysis of the same extracts, in order to validate the FTIR method as a good tool to investigate the fingerprint and to predict the composition of medicinal plants or to evaluate the quality and authenticity of different standardized formulas.

\section{Acknowledgements}

This work was partly supported from the ANCS-PNII projects AMPRENTAL (ID 51049 ) and PHYTOMED (ID 61008 ) (2007-2010).

\section{References}

Ahsan R, Islam M, Bulbul IJ, Musaddik A, Haque E (2009). Hepatoprotective Activity of Methanol Extract of Some Medicinal Plants Against Carbon Tetrachloride-Induced Hepatotoxicity in Rats. Europ J Sci Res 37:302-310.

Ali SM, Olivo M (2002). Bio-distribution and subcellular localization of hypericin and its role in PDT induced apoptosis in cancer cells. Int J Oncol 21:531-540.

Baer-Dubowska W, Szaefer H, Krajka-KuzniakV(1998).Inhibition of murine hepatic cytochrome P450 activities by natural and synthetic phenolic compounds. Xenobio 28:735-743.

Barnes J, Anderson LA, Philippson JD (2001). St. John's wort (Hypericum perforatum L): a review of its chemistry, pharmacology and clinical properties. J Pharmacol 53(5):583-600.

Basaga H, Poli G, Tekkaya C, Aras I (1997). Free radical scavenging and antioxidative properties of 'silibin' complexes on microsomal lipid peroxidation. Cell Biochem Funct 15:27-33.

Bender DA (2005). The promise of metabolomics. J Sci Food Agric 85:7-9.

Benninger J, Schneider HT, Schuppan D, Kirchner T, Hahn EG (1999). Acute hepatitis induced by greater celandine (Chelidonium majus). Gastroenterol 117:1234-7.

Betancor-Fernandez A, Pérez-Gálvez A, Sies H, Stahl W (2003). Screening pharmaceutical preparations containing extracts of turmeric rhizome, artichoke leaf, devil's claw root and garlic or salmon oil for antioxidant capacity. J Pharm Pharmacol 55(7):981-6.

Bone K (1996). Chelidonium-A medicinal poppy. MediHerb Professional Newsletter 49:1-3.

Bosisio E, Benelli C, Pirola O (1992) Effect of the flavanolignans of Silybum marianum L. on lipid peroxidation in rat liver microsomes and freshly isolated hepatocytes. Pharmacol Res 25:147-154.

Cabrera C (1996). Milk Thistle: A clinician's report. Medical Herbalism 6:1-5.

Duke JA (1985). CRC Handbook of Medicinal Herbs. CRC Press, Boca Raton, FL.

Gong F, Bo-Tang W, Yi-Zeng L, Foo-Tim C, Ying-Sing F (2006).
Variable selection for discriminating herbal medicines with chromatographic fingerprints. Analytica Chim. Acta 572:265-271.

Gong F, Zhang Q, ZhangJ (2009). Quality Assessment of Herbal Medicine with Chromatographic Fingerprint. J Drug Add, Educ Eradic 4:257-302.

Fan XH, Cheng YY, Ye ZL, Lin RC, Qian ZZ (2006). Multiple chromatographic fingerprinting and its application to the quality control of herbal medicines. Anal Chem Acta 555:217-224.

Favari L, Perez-Alvarez V (1997). Comparative effects of colchicine and silymarin on $\mathrm{CCl}_{4}$-chronic liver damage in rats. Arch Med Res 28:11-17.

Feher I, Deak G, Muzes G (1989). Liver-protective action of silymarin therapy in chronic alcoholic liver diseases. Orv Hetil 130:2723-2727.

Ferenci P, Dragosics B, Dittrich H, Frank H, Benda L, Lochs H, Meryn S, Base W, Schneider B (1989). Randomized controlled trial of silymarin treatment in patients with cirrhosis of the liver. J Hepatol 9:105-113.

Gilca M, Gaman L, Panait E, Stoian I, Atanasiu V (2010). Chelidonium majus-an integrative review: traditional knowledge versus modern findings. Forsch Komplementmed 17(5):241-248.

Giri L, Andola HC, Purohit VK, Rawat MSM, Rawal RS, Bhatt ID (2010). Chromatographic and spectral fingerprinting standardization of traditional medicines: an overview as modern tools. Res J Phytochem 4:234-241.

Gu Y, Qian D, Duan J, Wang Z, Guo J, Tang Y, Guo S (2010). Simultaneous determination of seven main alkaloids of Chelidonium majus L. by ultra-performance LC with photodiode-array detection. J Sep Sci 33:1004-1009.

Hashimoto A, Kameoka T (2008). Applications of infrared spectroscopy to biochemical, food, and agricultural processes. App Spectrosc Rev 43:416-451.

Hriscu A, Galesanu MR, Moisa L (1980). Cholecystokinetic action of an alkaloid extract of Chelidonium majus. Rev Med Chir Soc Med Nat Iasi 84:559-561.

Hussain K, Majeed MT, Ismail Z, Sadikun A, Ibrahim P (2009). Complementary and alternative medicine: quality assessment strategies and safe usage. Southern Med Rev 1(2):19-23.

Hussain K, Ismail Z, Sadikun A, Ibrahim P (2009a). Evaluation of Metabolic Changes in Fruit of Piper Sarmentosum in various Seasons by Metabolomics using Fourier Transform Infrared (FTIR) Spectroscopy. J Pharm Clin Res 1(2):68-71.

Istudor V (2003). Farmacognozie, Fitochimie, Fitoterapie. Farmacia 40(2):55-60.

Jeon HJ, Kang HJ, Jung HJ, Kang YS, Lim CJ, Kim YM, Park EH (2008). Antiinflammatory activity of Taraxacum officinale. J Ethnopharmacol 115(1):82-88.

Kurth H, Spreeman R (1998). Phytochemical characterization of various St.John Wort extracts. Adv Ther 15:117-128.

Li S, Han Q, Qiao C, Song J, Cheng CL, Xu H (2008). Chemical 
markers for the quality control of herbal medicines: an overview. Chinese Med 3(7):1-18.

Li H, Xia N, Brausch I, Yao Y, Förstermann U (2004a). Flavonoids from artichoke (Cynara scolymus L.) up-regulate endothelial-type nitric-oxide synthase gene expression in human endothelial cells. J Pharmacol Exp Ther 310(3):926932.

Li Y, Sun S, Zhou Q, Qin Z, Tao J, Wang J, Fang X (2004b). Identification of American ginseng from different region using FT-IR and two-dimensional correlation IR spectroscopy. Vibrat Spectroscopy 36:227-232.

Liang YZ, Xie P, Chan K (2004). Review: Quality control of herbal medicines. J Chromatography B 812:53-70.

Liu H, Sun S, Lv G, Chan KKC (2006). Study on Angelica and its different extracts by Fourier transform infrared spectroscopy and two-dimensional correlation IR spectroscopy. Spectrochim Acta Part A 64:321-326.

Lopus M, Panda D (2006). The benzophenanthridine alkaloid sanguinarine perturbs microtubule assembly dynamics through tubulin binding. A possible mechanism for its antiproliferative activity. FEBS J 273:2139-2150.

Malikova J, Zdarilova A, Hlobilkova A (2006). Effects of sanguinarine and chelerythrine on the cell cycle and apoptosis. Biomed Pap Med Fac Univ Palacky Olomouc Czech Repub 150:5-12.

Maloney V (2004). Plant metabolomics. BioTeach J 4:92-99.

Marakis G, Walker AF, Middleton RW, Booth JC, Wright J, Pike DJ (2002). Artichoke leaf extract reduces mild dispepsia in an open study. Phytomedicine 9(8):694-699.

Maros T, Rácz G, Katonai B, Kovács VV (1966). Effects of Cynara scolymus extracts on the regeneration of rat liver. 1. Arzneimittelforschung 16(2):127-129.

Mattoli L, Cangi F, Maidecchi A, Ghiara C, Ragazzi E, Tubaro M, Stella L, Tisato F, Traldi P (2006). Metabolomic fingerprinting of plant extracts. J Mass Spectrometry 41(12):1534-1545.

McGuffin M, Hobbs C, Upton R, Goldberg A (1997). American Herbal Products Association's Botanical Safety Handbook. CRC Press, Boca Raton, FL.

McPartland JM (1996). Viral hepatitis treated with Phyllanthus amarus and milk thistle (Silybum marianum): A case report. Complement Med Internat: 4(2):40-42.

Miguez MP, Anundi I, Sainz-PardoLA(1994). Hepatoprotective mechanism of silymarin: no evidence for involvement of cytochrome P4502E1. Chem Biol Interact 91:51-63.

Mitra S, Gole K, Samajdar K, Sur RK, Chakraborty BN (1992). Antihepatotoxic activity of Chelidonium majus. Int J Pharmacognosy 30:125-128.

Mitra S, Sur RK, Roy A, Mukherjee AS (1996). Effect of Chelidonium majus $\mathrm{L}$ on experimental hepatic tissue injury. Phytother Res 10:354-356.

Muriel P, Garciapina T, Perez-Alvarez V, Mourelle M (1992). Silymarin protects against paracetamol induced lipid peroxidation and liver damage. J Appl Toxicol 12:439-442.

Nahrstedt A, Butterweck V (1997). Biologically active and other chemical constituents of the herb of Hypericum perforatum L. Pharmcopsychiat 30:129-134.

Negi AS, KumarJK, Luqman S, Shanker K, Gupta MM, Khanuja SP (2008). Recent advances in plant hepatoprotectives: a chemical and biological profile of some important leads. Med Res Rev 28(5):746-772.

Perez-Garcia F, Adzet T, Cañigueral S (2000). Activity of artichoke leaf extract on reactive oxygen in human leukocytes. Free Rad Res 33(5):661-665.

Ritter R, Schatton WFH (1993). Clinical trial on standardized celandine extract in patients with functional epigastric complaints: Results of placebo-controlled double-blind trial. Comp Ther Med 1:189-193.

Saénz Rodriguez T, García Giménez D, de la Puerta Vázquez R (2002). Choleretic activity and biliary elimination of lipids and bile acids induced by an artichoke leaf extract in rats. Phytomedicine 9(8):687-693.

Salmi HA, Sarna S (1982). Effect of silymarin on chemical, functional, and morphological alterations of the liver; a double blind controlled study. Scand J Gastroenterol 17:517-521.

Schultz H, Baranska M (2007). Identification and quantification of valuable substances by IR and Raman spectroscopy. Vibrational Spectroscopy 43:13-25.

Schütz K, Muks E, Carle R, Schieber A (2006). Separation and quantification of inulin in selected artichoke (Cynara scolymus L.) cultivars and dandelion (Taraxacum officinale WEB. ex WIGG.) roots by high-performance anion exchange chromatography with pulsed amperometric detection. Biomed Chromatography 20(12):1295-1303.

Singleton VL (1999). Analysis of total phenols and other oxidation substrates and antioxidants by means of FolinCiocalteu reagent. Methods Enzymol 299:152-178.

Utrilla MP (1996). Natural products with hepatoprotective action. Methods Find Exp Clin Pharmacol 18(B):11-12.

Vavreckova C, Gawlik I, Muller K (1996). Benzophenanthridine alkaloids of Chelidonium majus; I. Inhibition of 5-and 12-lipoxygenase by a non-redox mechanism. Planta Med 62:397-401.

Wang MF, Simon JE, Aviles IF, He K, Zheng QY, Tadmor Y (2003). Analysis of antioxidative phenolic compounds in artichoke Cynara scolymus L. J Agr Food Chem 51:601608.

WHO (2003). WHO guidelines on Good Agriculture and Collection Practices (GACP) for medicinal plants. Geneva.

Williams CA, Goldstone F, Greenham J (1996). Flavonoids, cinnamic acids and coumarins from the different tissues and medicinal preparations of Taraxacum officinale. Phytochem 42(1):121-127.

Yadav NP, Dixit VK (2008). Recent approaches in herbal drug standardization. Int J Integr Biol 2:195-203.

Zdařilová A, Malikova J, Dvorak Z, Ulrichova J, Simanek V (2006). Quaternary isoquinoline alkaloids sanguinarine and chelerythrine. In vitro and in vivo effects. Chemicke Listy 100:30-41. 